Bull, Mater. Sci., Vol. 4, No. 3, May 1982, pp. 341-346. (C) Printed in India.

\title{
Indian sounding rockets for material science experiments
}

\author{
T M K MARAR and K S SHYLA \\ Physics Section, ISRO Satellite Centre, Bangalore 560 058, India \\ MS rcceived 17 June 1980
}

\begin{abstract}
The capabilities of Indian sounding rockets for conducting material science experiments are briefly described in this paper.
\end{abstract}

Keywords. Sounding rockets ; material science experiments.

\section{Introduction}

Sounding rockets provide one of the simplest and cheapest means of conducting material science experiments under microgravity conditions. The duration of residual accelerations $\leqslant 10^{-4} \mathrm{~g}$ during the coasting phase of the rocket can be of several minutes and is sufficiently long for conducting a number of investigations. Racket payloads are simpler to fabricate and are less expensive to try out new ideas. Further, the turn-around time between the conception and execution of rocket experiments is typically of the order of an year in contrast to 4 to 5 years of time needed for realising a satellite experiment. Hence it is always advantageous and often desirable before one attempts to fly them on satellites. Rocket payloads in principle can be recovered and refurbished far reuse. One gets sufficient experience in conducting various space environmental tests and qualification of the experiment. Further, the safety requirements on rocket payloads are less stringent.

It is therefore clear from the above considerations that rocket experiments form a parallel and complementary activity to conduct microgravity materials research on future space missions. The Indian Space Research Organisation (ISRO) has developed a number of sounding rockets with varying capabilities that may be used for conducting a number of material scicnce experiments in microgravity conditions. We will bricfly revicw in this paper some of the capabilities of these rockets and outline the requirements that have to be satisfied by experimental payloads.

\section{Sounding rockets of ISRO}

The sounding rockets of ISRO include the Menaka series of rockets which are primarily meant for meteorological studies, the Rohini series and the Indian made Centaures for upper atmospheric investigations. Some of the salient features of these rockets are given in Table 1 (Sudhakar 1976). Menaka II, 
Table 1. Salient features of ISRO sounding rockets.

\begin{tabular}{|c|c|c|c|c|c|c|c|}
\hline \multirow{2}{*}{ Details } & \multicolumn{6}{|c|}{ Type of rockets } & \multirow[b]{2}{*}{ RH-560B } \\
\hline & Menaka II & RH-300 & Cent IIB & RH-560 & RH-300B & RH-560S & \\
\hline No. of stages & 2 & 1 & 2 & 2 & 2 & 1 & 2 \\
\hline Diameter $(\mathrm{mm})$ & 122 & 305 & 305 & 561 & 305 & 561 & 561 \\
\hline Length (mm) & 3778 & 4090 & 6310 & 7933 & 6465 & 5856 & 9943 \\
\hline Launch wt (kg) & 63 & 369 & 530 & 1344 & 551 & 1457 & 2495 \\
\hline $\begin{array}{l}\text { Typical payload } \\
\text { weight }(\mathrm{kg})\end{array}$ & $4 \cdot 5$ & 50 & 60 & 90 & 60 & 150 & 250 \\
\hline Spin rate (rps) & 6 & 6 & 5 & $6 \cdot 5$ & 6 & 5 & $2 \cdot 5$ \\
\hline $\begin{array}{l}\text { Apogee at } \\
85^{\circ} \mathrm{QB}(\mathrm{km})\end{array}$ & 59 & 135 & 148 & 390 & 200 & 210 & 420 \\
\hline
\end{tabular}

Centaure IIB, Rohini-300, Rohini-560 and Rohini 560S are now available for scientific experiments while the remaining are under development. The above rockets are all spin-stabilised and are unguided. Payload recovery is not available at present. This is, therefore, the major shortcoming of our racket facilities for carrying out material pracessing experiments. Material science experiments however, can still be performed if one provides appropriate telemetry of data from the experiment.

Figure 1 gives a plat of the altitude versus payload weight capability of ISRO's sounding rockets (Sudhakar 1976). It is clear that reasonable payload weights of the order of 100 to $150 \mathrm{~kg}$ can be flown on Rohini 560 upto altitudes of 350$270 \mathrm{~km}$. Figure 2 gives the flight duration above $110 \mathrm{~km}$ (at acceleration levels $>10^{-4} \mathrm{~g}$ ) versus payload weight for the Centaure- $\Pi B$, Rohini 560 and Rohini 560 s. One finds that the Rohini 560 offers microgravity conditions to a pay-load of $110 \mathrm{~kg}$ for a duration of about $7 \mathrm{~min}$ which indeed is a reasonable time for canducting a number of material science investigations.

\section{Comparison with European rockets}

The Skylark rockets manufactured by the British Aerospace Corporation have been extensively used by the German-Swedish material science programme called TEXUS (Technological Experiments under Microgravity). Skylark 7 and Skylark 14 have been used for these experiments (Brown 1979). The paylaods are recoverable in these cases. Figure 3 gives the apogee versus payload weight performance and the du ration of microgravity $\left(\leqslant 10^{-4} \mathrm{~g}\right)$ conditions for the Skylark 7 and 14 rockets (Brown 1979). In table 2 we compare some of the salient features of Rohini rockets with those of Skylarks.

Once again we are led to the conclusion that the Indian rocket capabilities are comparable in performance for material science experiments to the best European rockets except for the unfortunate fact that our payloads are not recaverable. 


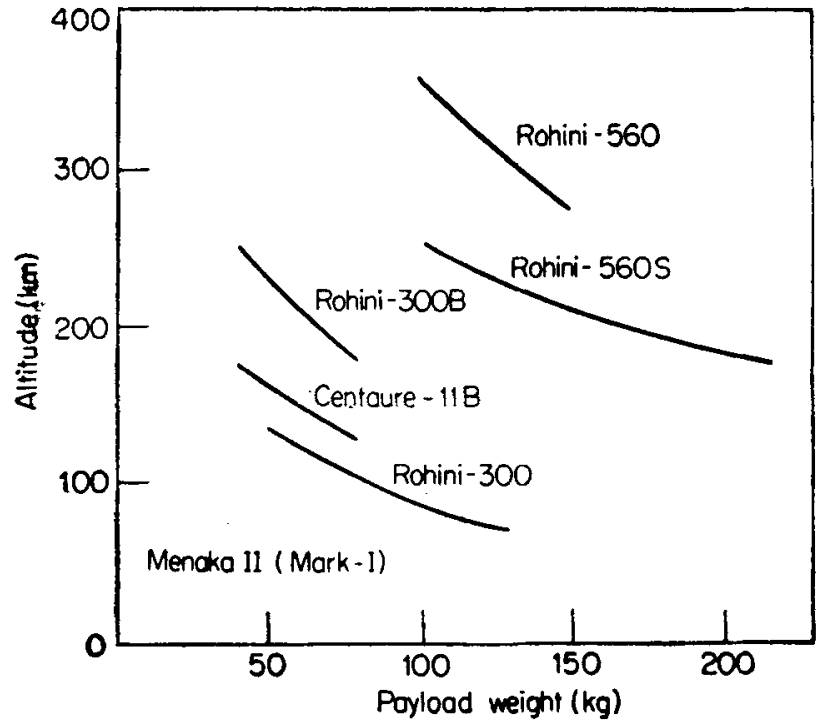

Figure 1. Comparative study of flight altitude of ISRO sounding rockets.

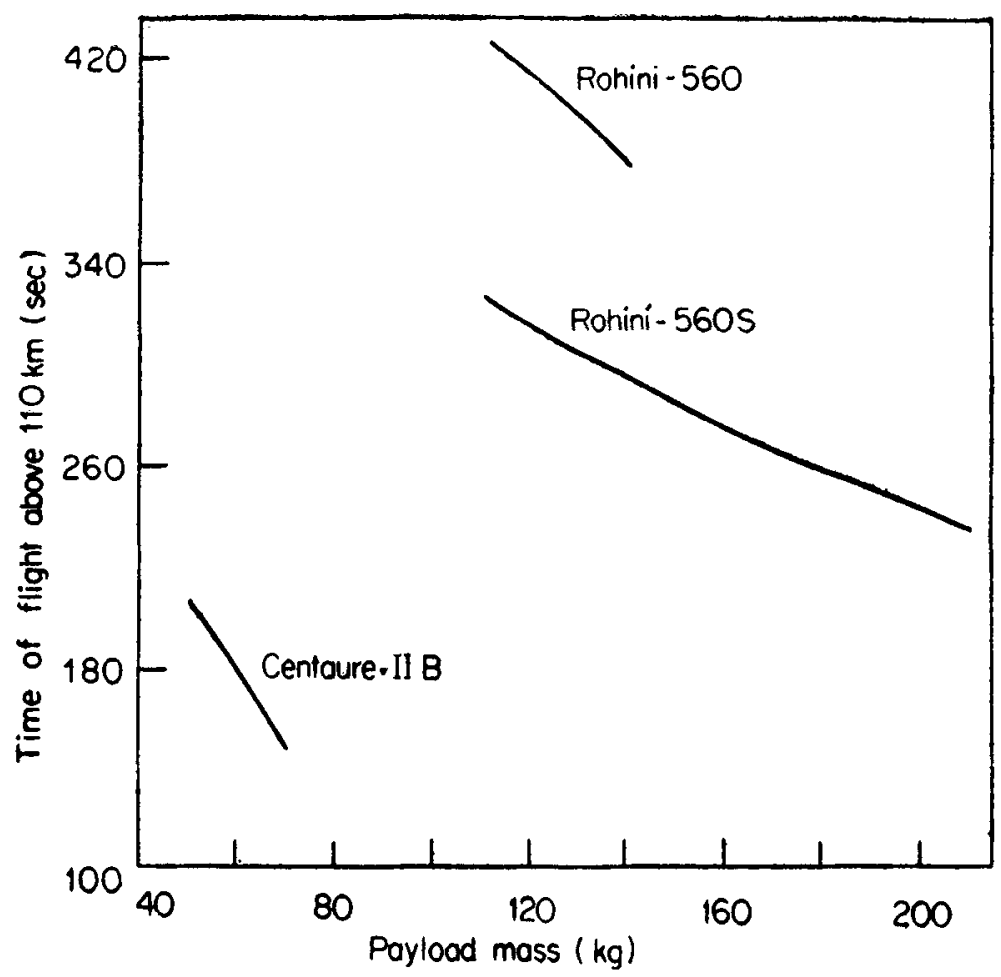

Figure 2. Comparative study of flight duration above $110 \mathrm{~km}$ of ISRO sounding rockets. 


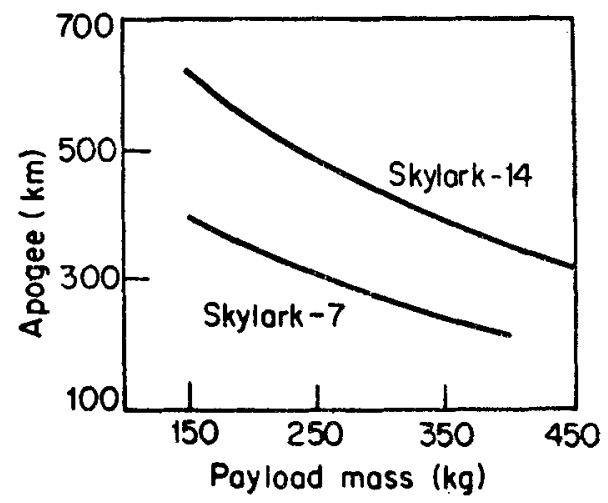

Skylark Apogec performance

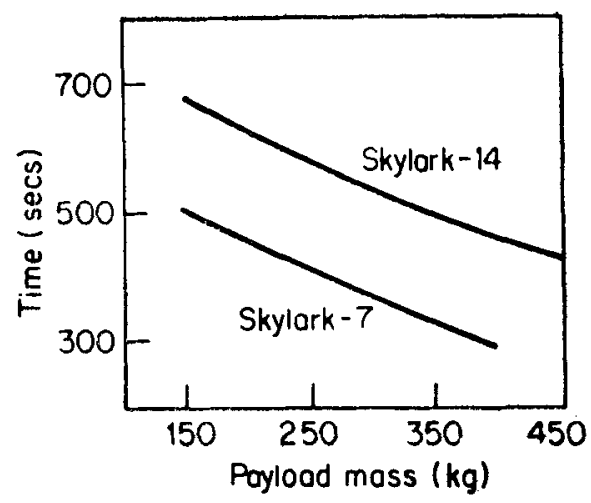

Skylark experiment time at $10^{-4} \mathrm{~g}$

Figure 3. Study of performances of Skylark 7 and Skylark 14.

Table 2. Rohini and Skylarks-A comparison.

\begin{tabular}{|c|c|c|c|c|}
\hline Features & $\begin{array}{c}\text { Rohini } \\
560\end{array}$ & $\begin{array}{l}\text { Rohini } \\
560 \mathrm{~S}\end{array}$ & $\begin{array}{c}\text { Skylark } \\
7\end{array}$ & $\begin{array}{l}\text { Skylark } \\
14\end{array}$ \\
\hline $\begin{array}{l}\text { 1. Typical payload dimensions } \\
\text { Diamoter (mm) } \\
\text { Length (mm) }\end{array}$ & $\begin{array}{r}305 \\
1730\end{array}$ & $\begin{array}{r}561 \\
2000\end{array}$ & $\begin{array}{r}440 \\
4200\end{array}$ & $\begin{array}{r}440 \\
4200\end{array}$ \\
\hline 2. Maximum payload weight $(\mathrm{kg})$ & 150 & 220 & 400 & 450 \\
\hline 3. Apogee for $150 \mathrm{~kg}$ payload $(\mathrm{km})$ & 280 & 220 & 400 & 620 \\
\hline $\begin{array}{l}\text { 4. Time of flight under microgravity } \\
\left(10^{-4} \mathrm{~g}\right)(\mathrm{sec})\end{array}$ & 240 & 150 & 505 & 680 \\
\hline 5. Payload recovery & No & No & Yes & Yes \\
\hline
\end{tabular}

\section{Get-away specials on ISRO rockets}

NASA has announced the availability of opportunities for flying small, autonomous payloads in most of the future shuttle flights. These are called Get-away specials (GAS) and are expected to offer the most economical method of carrying out autonomous experiments in space. The expcrimental volume and maximum allowable weight are specified by NASA. Of the available options, the two with volumes of $0.04 \mathrm{~m}^{3}$ and $0.07 \mathrm{~m}^{3}$ with maximum masses of $27.3 \mathrm{~kg}$ and $45.4 \mathrm{~kg}$ respectively can be flown for trial experiments on ISRO's rackets. Each shuttle flight can accommodate an avcrage of four GAS payloads and hence the flight opportunities are considerably greater for GAS than for spacelab experiments. The GAS payload should contain the experiment, its electronics, photography, battery pack, data starage, interface with the shuttle, the experiment programme timer, thermal control and an accelerometer for recording the $g$ levels. In other words, it is essentially a mini-satellite. Trial flights of GAS payloads on rockets are therefore a desirable, parallel and complementary activity to their final flight on the shuttle. 
Table 3. Typical specifications for qualification of payloads.

\begin{tabular}{|c|c|c|c|}
\hline & $\begin{array}{c}\text { Frequency Range } \\
\text { (HZ) }\end{array}$ & $\begin{array}{l}\text { Amplitude } \\
\text { or level }\end{array}$ & $\begin{array}{c}\text { Sweep rato } \\
\text { (Octaves/min.) }\end{array}$ \\
\hline & $10-35$ & $1.5 \mathrm{~mm}$ & 2 \\
\hline & $35-90$ & $4 \cdot 0 \mathrm{~g}$ & 2 \\
\hline & $90-500$ & $9 \cdot 0 \mathrm{~g}$ & 1 \\
\hline & $500-2000$ & $6.0 \mathrm{~g}$ & 2 \\
\hline 1. Vibration & \multicolumn{3}{|c|}{ Sinusoidal (along ZZ axis) } \\
\hline 2. Spin & \multicolumn{3}{|l|}{$6 \mathrm{rps}$ for $3 \mathrm{~min}$} \\
\hline 3. Vacuum & \multicolumn{3}{|c|}{$10^{-4}$ to $10^{-6}$ Torr for $30 \mathrm{~min}$} \\
\hline 4. Accoleration & \multicolumn{3}{|l|}{$25 \mathrm{~g}$ for $2 \mathrm{~min}$} \\
\hline 5. Shock & \multicolumn{3}{|c|}{$50 \mathrm{~g}$ for 10 milli sec. (half sinusoidal) } \\
\hline 6. Temperature & \multicolumn{3}{|l|}{$70^{\circ} \mathrm{C}$ for $10 \mathrm{~min}$} \\
\hline
\end{tabular}

\section{Requirements on experimental payloads}

All payloads that are to be flown on ISRO sounding rockets have to be subjected to space environmental tests as per the specifications laid down by the management office of the Rohini sounding rocket programme of Vikram Sarabhai Space Centre in Trivandrum. A typical test specification that applies to the prototype of an experiment is given in table 3 (Sudhakar 1976).

The Thumba Equatorial Rocket Launching Station, (TERLS) provides a number of facilities to experimenters. These facilities include complete FM/FM telemetry system conforming to IRIG standards and channels, trasmitters with $1 \cdot 5$ and $4 \cdot 5$ watts power at $225-260 \mathrm{MHz}$ frequency, sequences, magnetameters and sun sensors for aspect determination, $500 \mathrm{MHz}$ tone receiver, hause keeping sensors such as accelerometers, pressure pick-ups and temperature sensors, timers, S- and C-band radar transponders, telecommand systems for experiment operational requirements, pyrodevices, nose cone ejection facility, door-ejection and payload separation systems. The ground support facilities at TERLS include two FM/FM telemetry stations conforming to IRIG standards, a. COTAL LV $\rightarrow 300$ radar tracking station, DOVAP tracking, metearalogical support for launch and a number of other facilities such as computers, inter-communication, links, photography etc.

Scientists wishing to use ISRO sounding rockets for material science experiments may contact the Scientific Secretary, ISRO Head Quarters, Cauvery Bhavan, District Office Road, Bangalore 560009 , for rocket allotment, and the programme Manager, Rohini Sounding Rocket Programme, Vikram Sarabhai Space Centre, Trivandrum 695022, for any special requirements and launch support. 


\section{References}

Brown D J 1979 Skylark sounding racket facilities for material science experiments in Material Science in space; Proc. 3rd European Symposium, Grenoble, ESA-SP-142 (1979)

Sudhakar V 1976 Sounding rockets of ISRO, ISRO-VSSC Technical Note 02-76. 